\title{
A Novel Approach to Treating Acute Hamstring Functional Neuromuscular Disorder-Effects of Primal Reflex Release Technique
}

\author{
Lucas Bianco, DAT, LAT, ATC' ; James May, DAT, LAT, ATC²; Alan Nasypany, EdD, LAT, ATC2 \\ 'BIOKINETIX, Chicago, IL; ${ }^{2}$ University of Idaho, Moscow, ID
}

\section{ABSTRACT}

Hamstring injuries have an occurrence rate of 3.05 per 1000 athlete exposures in intercollegiate athletics. Current clinical practice recommendations for rehabilitation of hamstring injuries are based on pathoanatomical muscle tissue healing timeframes. The purpose of this study was to examine the effects of modulating the nervous system with Primal Reflex Release Technique (PRRT) in patients clinically diagnosed with functional neuromuscular hamstring muscle-related disorder (FNHD). In this a priori case series, PRRT was utilized in four patients participating in intercollegiate, National Collegiate Athletic Association Division II, athletics to evaluate Numeric Pain Rating Scale (NRS) for current pain, Disablement of the Physically Active (DPA) scale, modified Patient Specific Functional Scale (PSFS), and Active Knee Extension Test (AKET). The initial pre-treatment to post-treatment average difference for NRS $\left(3.25 \pm 2.5\right.$ points) and AKET $\left(11 \pm 2.16^{\circ}\right)$ improved by an amount that satisfied MCID and MCD respectively. The pre-treatment to one-week follow-up average difference for NRS $(5.5 \pm 2.3$ points), PSFS $\left(4.75 \pm 2.5\right.$ points), and AKET $\left(20.5 \pm 14^{\circ}\right)$ improved by an amount that satisfied MCID or MCD. The average timeline for discharge to full unrestricted activity was 2.75 days. In the four patients classified with a functional neuromuscular muscle disorder (FNMD), PRRT was utilized as the only manual therapy intervention. Through modulation of the nervous system, the outcomes reported by the patients were both meaningful and clinically significant. Based on the results and the current standard of care for similar patients, the need for further research into this paradigm is warranted. Hamstring injuries continue to be a significant clinical injury in the athletic patient population. A thorough evaluation and appropriate classification of muscle injury can help clinicians decided an effective treatment for the patient. Clinicians seeking to improve patient outcomes may benefit from considering a paradigm that modifies the neural allostatic loads.

\section{Key Phrases}

Autonomic nervous system, patient-reported outcomes, clinician-rated outcomes

\section{Correspondence}

Dr. Lucas Bianco, 3205 Street Lynchburg, VA 24501.

E-mail: lucasbianco4915@gmail.com

\section{Full Citation}

Bianco L. A Novel Approach to Treating Acute Hamstring Functional Neuromuscular Disorder-Effects of Primal Reflex Release Technique. Clin Pract Athl Train. 2019;2(1):19-31. https://doi.org/10.31622/2019/0001.5.

Submitted: December 9, 2018 Accepted: February 26, 2018

\section{INTRODUCTION}

$\mathrm{H}$ amstring injuries are a common pathology within physically active patient populations. ${ }^{1-6}$ Injury to the hamstring muscle complex can present as tissue damage leading to pain and functional limitations. 1-4,5-8 Structural damage, ranging from micro-trauma to macro-trauma, can occur when the force placed on the hamstring muscle is greater than the mechanical limits of the tissue. 9,10 Functional limitations, not structural damage, are frequently used to classify a patient with a hamstring injury, and determine treatment parameters based on recommendations of tissue healing timeframes. ${ }^{6-}$ 8,11 It is possible that a portion of these injuries have minimal or no structural damage and are FNMDs, thus they do not need to adhere to the recommended tissue healing timeframes.

Hamstring injuries are prevalent in the intercollegiate athletic population, with a rate of 3.05 per 1000 athlete exposure. ${ }^{12}$ The goals of hamstring rehabilitation include decreasing pain, restoring function, and returning to the prior level of sports performance with minimal risk of reinjury. 1,2,7,11 Previous research on hamstring treatment and return to play programs has been completed for patients classified with hamstring injury. However, the re-injury rates for this clinical significant injury have been consistent over the past 20 years. $1,2,4,8,11-13$ With an increased risk of re-injury rate in intercollegiate athletics, further research is required to determine more effective interventions and treatment theories to decrease pain, restore range of motion (ROM), and improve function following classification of a hamstring injury. 
The pathoanatomical evaluation is recommended as the means for assessing a patient with a possible hamstring injury. $1,2,7,8,10,14$ The widely used, O'Donoghue Muscle Injury Classification system correlates tissue damage to loss of function. ${ }^{15}$ Based on this classification system, patients who present with pain and decreased function would be classified with a grade I or II hamstring strain. A recent consensus statement on muscle injuries in sport provides a new comprehensive classification system. ${ }^{16}$ The Munich Muscle Injury Classification system (Figure 1) was used by the treating clinician (TC) to sub-classify these patients. Based on this new classification system, patients treated in this case series would be classified as having a FNMD. The neural component of a musculoskeletal injury can easily be overlooked as it is not commonly associated or treated under the tissue model. ${ }^{17}$ As rehabilitation theories evolve to meet the progressive neurophysiologic research, clinicians may desire interventions purposed to create ideal function of the neurological system, rather than protocols encompassing the myopic muscle tissue healing model.

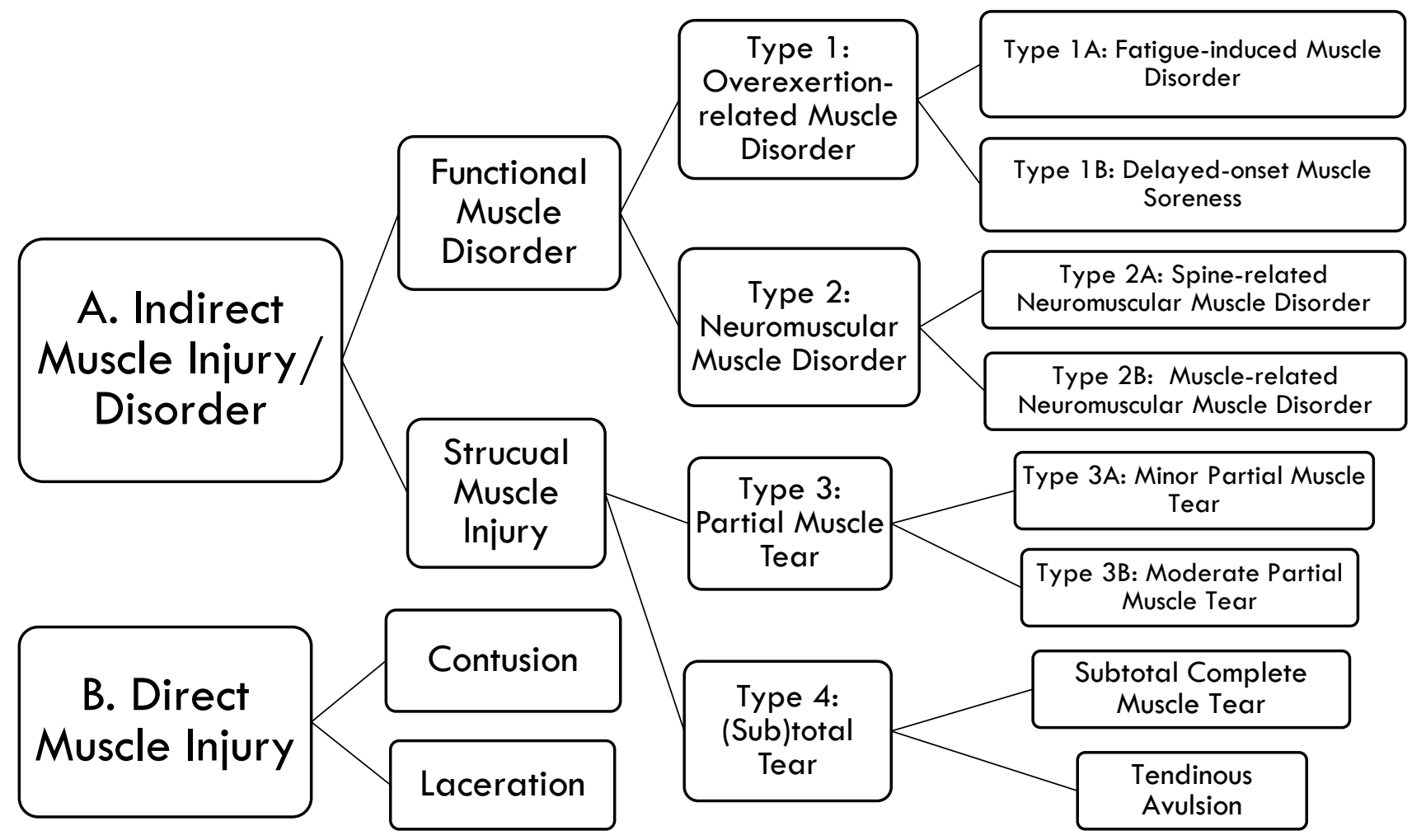

Figure 1. Munich Muscle Classification 16

Patients with hamstring injuries in this study were classified with a Type 2A Muscle-related Neuromuscular Muscle Disorder and treated with PRRT, an innovative neurophysiological approach to treatment Patients with hamstring injuries in this study were classified with a Type 2B Muscle-related Neuromuscular Muscle Disorder and treated with PRRT, an innovative neurophysiological approach to treatment. 
The central nervous system (CNS) and peripheral nervous system (PNS) are directly related, and function in unison to provide appropriate sensory information to the brain to maintain a state of allostasis throughout the body. ${ }^{18-20}$ Allostatic modulations in loading of the muscle tissue are often due to facilitated neurons and/or inhibited neurons creating abnormal function. ${ }^{20}$ Neurophysiologist, Sir Charles Sherrington, introduced the law of reciprocal innervation which is used in therapeutic techniques, such as proprioceptive neuromuscular facilitation, to relax the agonist muscle via reflexive stimulation of the antagonist muscle. ${ }^{21}$ The use of reciprocal innervation may be an effective treatment when the nervous system is in need of a modulating external stimulus. ${ }^{22}$ Expanding on this theory, withdrawal and startle reflexes that lead to muscle spasm and possibly pain can be due to mal-adaptation or abnormal stimulation of the nervous system. ${ }^{19}$ As a result of trauma (e.g., high speed running or agility movements), the nervous system may remain "up-regulated" and unable to restore a state of more ideal allostasis. In this up-regulated state, the use of an external stimulus to reset the CNS can resolve pain and restore function instantly. 19,23 The creator of PRRT, John lams, recognized that reflex responses to startling and/or painful events may persist in the form of facilitated or inhibited muscles, which leads to compensatory patterns, pain, dysfunction. ${ }^{23}$ Through modulating the CNS through the PNS, PRRT, an innovative treatment paradigm, can help reset the nervous system to a more ideal allostatic load following a traumatic incident such as a mechanism of injury leading to a hamstring injury. The use of PRRT in clinical practice has been demonstrated in the literature. ${ }^{24-26}$ The purpose of this study was to examine the effects of modulating the nervous system with PRRT in patients classified with functional neuromuscular hamstring musclerelated disorder (FNHD).

\section{PATIENTS}

Four patients ( 3 males and 1 female) averaging (19.75 \pm 1.5 years of age) actively participating in intercollegiate athletics (Table 1) reported to the athletic training clinic with posterior thigh pain. All four patients were evaluated by a certified athletic trainer and met criteria to be included in this study. Each patient was classified with FNMD and treated by the same athletic trainer with four years of clinical practice experience who had completed, The Primal Reflex Release Technique ${ }^{\mathrm{TM}}$ Home Study Course, and The Primal Reflex Release Technique ${ }^{\mathrm{TM}}$ LiveTraining Seminar. Based on the a priori design, the patients were not treated with any other therapeutic interventions. Patient-oriented evidence (POE) and clinician-oriented evidence (COE) outcome measures were collected for each patient over the course of treatment. The Numeric Pain Rating Scale (NRS) for current pain, Disablement of the Physically Active (DPA) scale, and modified Patient Specific Functional Scale (PSFS) were all included as POE. The COE classified measure was the, Active Knee Extension Test (AKET), and hamstring manual muscle test (MMT). The Institutional Review Board (IRB) of the two universities involved in this study approved the collection and dissemination of outcomes. All participants provided written

Table 1. Demographics and Evaluation Information

\begin{tabular}{|c|c|c|c|c|c|}
\hline Patient & Age & Gender & Sport & $\begin{array}{l}\text { Location of Pain in } \\
\text { Posterior Thigh }\end{array}$ & Involved Side \\
\hline 1 & 18 & Female & Cross Country & \multirow{3}{*}{$\begin{array}{l}\text { Lateral Distal Third } \\
\text { Middle Third } \\
\text { Lateral Middle } \\
\text { Third }\end{array}$} & Right \\
\hline 2 & 19 & Male & Soccer & & Left \\
\hline 3 & 21 & Male & Basketball & & Left \\
\hline 4 & 21 & Male & Basketball & $\begin{array}{c}\text { Medial Proximal } \\
\text { Third }\end{array}$ & Left \\
\hline
\end{tabular}


consent to have their non-identifiable information included in this study.

At the time of initial evaluation, each patient reported pain with a decrease in active ROM and function in the affected extremity compared bilaterally. Due to the short time period from onset of injury to evaluation of the patient (within 1-2 days), lack of structural damage diagnosis, and Munich muscle injury classification each patient was determined to have sustained a neuromuscular muscle disorder. One patient selfreported a previous "hamstring strain" on his contralateral side, while the other patients reported no previous hamstring pathology. Following the evaluation, POE and COE measures were completed. Patients were included if they had the following outcome scores; NRS of $\geq 2 / 10$, AKET measurement of $\leq 70^{\circ}$ on involved side, and a PSFS score of $\leq 8 / 10$ (Table 2).

\section{INTERVENTION}

The initial PRRT treatment session was completed immediately following the initial evaluation and collection of baseline patient outcome measures. The patient was positioned supine on a treatment table for all treatments. Then the TC provided a tactile stimulus the patient's muscle bellies and tendons, or a quick movement the patient's limb to create a reflexive response. The stimulus activates proprioceptors in the local tissue through reciprocal innervation that can lead to a more ideal allostatic load in the nervous system. ${ }^{21-23}$ Starting with the involved side, each technique was completed for approximately 12 seconds, followed by the intervention on the contralateral limb. Four PRRT treatment techniques in the same sequence were utilized on each patient.

The intervention consisted of the following sequence: Hamstring Down-Regulate (dR) (Figure 2), Gastrocnemius Reset (Figure 3), Medial Knee/ Sacroiliac (SI) Joint Reset (Figure 4), and

Copyright (C) by Indiana State University
SI Bilateral Release (Figure 5), and was completed bilaterally, for a total of 2-3 minutes per session. After completion of the treatment, the patient stood up and then walked the length of the clinic two times, a total of approximately 60 feet. Then AKET and PSFS were reassessed, along with the NRS, at the conclusion of the initial treatment session.

\section{OUTCOME MEASURES}

The NRS, PSFS, MMT, and AKET were assessed at the following time-points: pre- and post-initial treatment session, discharge, one-week, and sixweek follow-up assessment. The DPAS was collected at the pre-initial treatment session, oneweek, and six-week follow-up assessment. Following the evaluation and collection of initial outcome measures, each patient received the PRRT sequence described below. Total number of treatments and days to discharge were tracked for each patient.

\section{Numeric Rating Scale \& Disablement of the} Physically Active

The NRS and DPAS patient-reported outcomes assessments measured each patient's perception of pain and disablement. The NRS is an 11 -point pain scale where 0 is "no pain" and 10 is "the worst pain imaginable." Scores reported for the NRS represent patient reported current pain in a weight bearing position (i.e. standing) at the time of assessment. A change of 2 points or greater is considered a Minimal Clinically Important Difference (MCID) for the NRS. ${ }^{27}$ The DPAS was designed and validated for assessing disablement in physically active individuals. A 64-point scale with 16 possible identifiers of disablement individually scored on a 5 -point Likert scale where zero is "no issues" and 4 is a "severe" issue. For acute conditions, a MCID is reached with a 9-point difference in scores. ${ }^{28}$ 
Table 2. Inclusion and Exclusion Criteria

\begin{tabular}{ll}
\hline Inclusion & Exclusion \\
\hline Acute, sudden posterior thigh pain NRS of $\geq 2 / 10$ & Gross deformity \\
MOI: acceleration or deceleration during running & Visible ecchymosis \\
Tender area to palpate on hamstring & Previous hamstring strain \\
Weakness compared bilaterally with knee flexion $<5 / 5 \mathrm{MMT}$ & within 6 months \\
Asymmetrical range of motion $>5^{\circ}$ & No specific MOI \\
Involved side AKET measurement of $<70^{\circ}$ & \\
Modified PSFS $\leq 8 / 10$ & \\
\hline
\end{tabular}

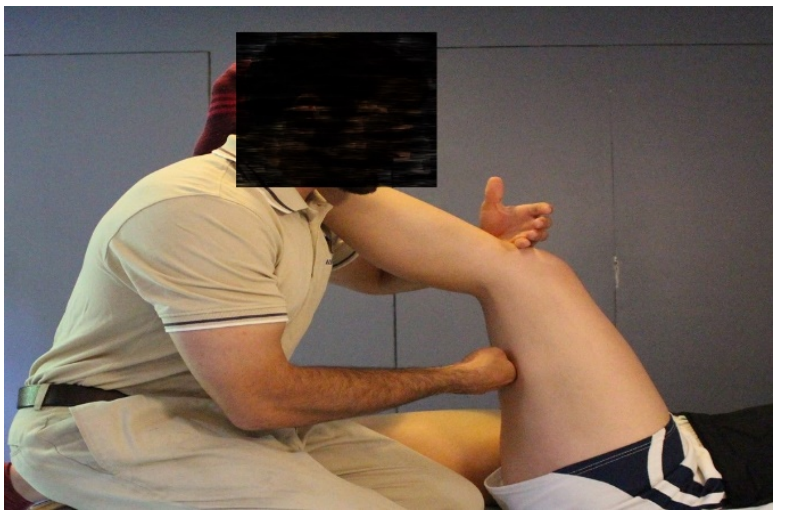

Figure 2. Hamstring down-regulate (dR). $22-23$ Patient rests foot on the TC's shoulder while stimulation is applied to the patella tendon and each hamstring (semitendinosus, semimembranosus, and biceps femoris) muscle bellies.

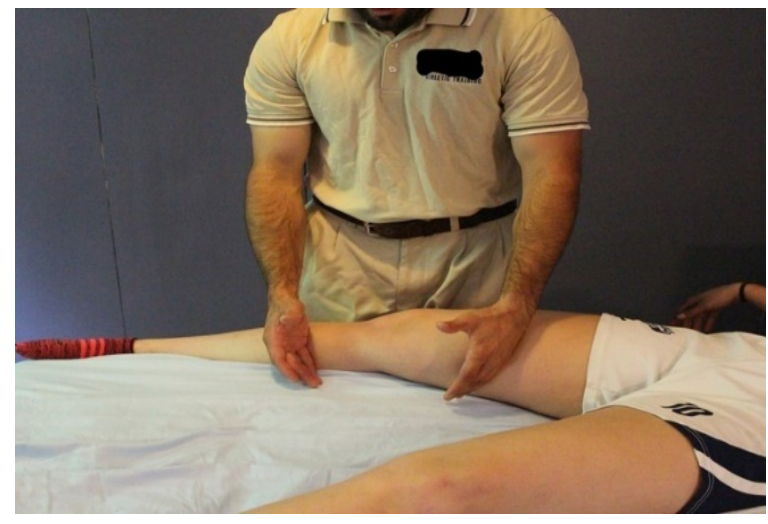

Figure 4. Medial knee/Sacroiliac (SI) joint Reset. ${ }^{23}$ Stimulation is provided to the adductor magnus muscle superior to the knee and pes anserine inferior to the knee.

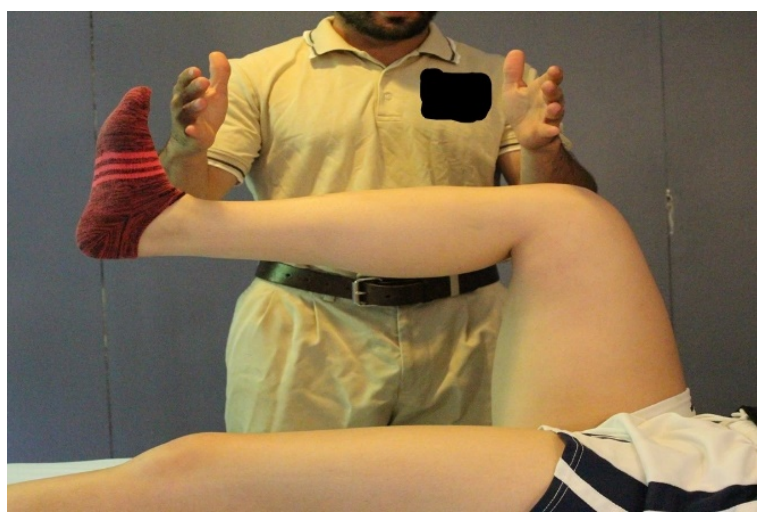

Figure 3. Gastrocnemius Reset. ${ }^{23}$ Patient maintains hip and knee flexion and ankle dorsiflexion while the TC applies stimulation to the patella tendon and ankle dorsiflexors (tibialis anterior, and extensor digitorum longus).

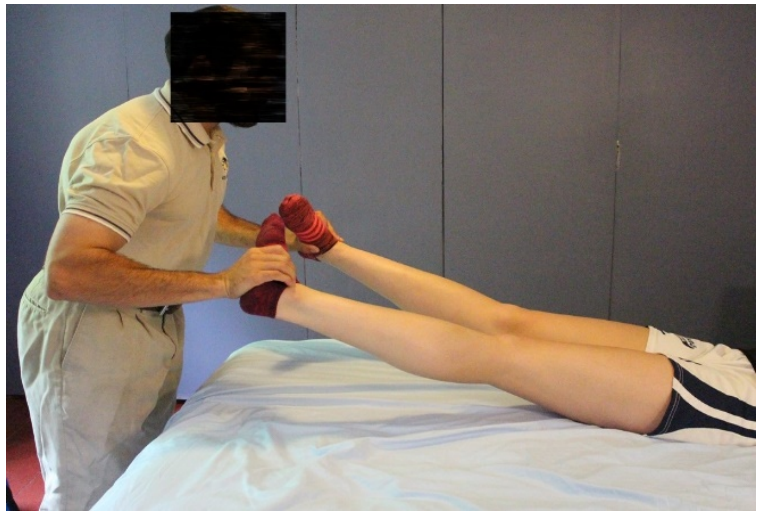

Figure 5. SI Bilateral Release. ${ }^{22}$ The TC provided an external rotation stimulus into external hip rotation which the patient reacted against activating his/her internal hip rotators. 


\section{Range of Motion (ROM)}

To objectively assess ROM, the AKET was completed. The AKET is completed with the patient lying supine. First, the Clinometer phone application (plaincodeTM, Stephanskirchen, Germany) was utilized to position the angle of hip flexion at $90^{\circ}$ by placing the device on the posterior aspect of the thigh. Once in $90^{\circ}$ of hip flexion the patient was advised to straighten at his/her same knee while the patient maintained a fixed $90^{\circ}$ hip flexion position. 29,30 The Clinometer was then moved to the anterior tibial shaft to assess the amount of knee extension which was recorded as the AKET measurement, a straight knee was considered $90^{\circ}$ of movement. The standard error of measurement (SEM) has been reported at $3 \cdot 8^{\circ} .29,30$ The Minimal Detectable Change (MDC) has been recorded between $9.7^{\circ}$ and $10.5^{\circ} .29,30$

\section{Strength Testing}

Manual Muscle Tests were included to grade muscular strength during evaluations. ${ }^{31}$ Each patient was positioned prone and queved to flex his/her knee through the full ROM. If the patient could not move through the full ROM against gravity a grade of 2 was documented. No patients had a trace amount of movement, grade 1. When full ROM accomplished against gravity with no pain and the same ROM compared bilaterally a grade of 3 was documented. Next, the TC placed force on the posterior aspect of the calcaneus while the patient's knee was flexed to $90^{\circ}$ and then asked the patient to resist. If the patient was able to resist the same force bilaterally a grade of 5 was recorded, grade of 4 was provided when full ROM was obtained but one side was unable to resist the same force as the contralateral side. ${ }^{31}$

\section{Patient Specific Functional Scale}

For assessment of perceived function, a modified PSFS was implemented for uniformity between

Copyright (C) by Indiana State University All rights reserved. ISSN Online 2577-8188 patients and the a priori design. The PSFS classified each activity on an 11 -point scale with 10 defined as, able to perform the same as before injury. An MCID is established for the PSFS when a score for a single activity changes by 3 points. ${ }^{32}$ For the single activity, the patient was asked to stand with his/her feet about an inch apart and then cued to "bend forward and touch your toes". Following completion of the task the patient was asked to score the task on the 11 -point scale.

\section{RESULTS}

Four patients were evaluated and treated by the TC and were discharged to full unrestricted activity in an average of 2.75 days from the start of treatment (Table 3). During the treatment sessions, POE and COE outcomes were collected to assess the patient's pain and function. Immediately following the initial treatment all the patients reported a decrease in pain that met MCID standards and three out of the four patients had an increase AKET measurement that was greater than the MDC (Table 4). Prior to returning to full unrestricted activity (i.e. competitive event) the patients had decrease in NRS, as well as increases in PSFS, MMT and AKET (Table 5 \& Table 6). At the one-week assessment all the patients reported a MCID for NRS and DPAS while all but one had a MCID recorded for PSFS (Table 6). The AKET measures for each patient were all greater than the MDC at the six-week follow-up assessment (Table 5). At the six-week follow-up after discharge each patient reported no re-injury and maintained outcome scores.

\section{DISCUSSION}

The initial treatment of PRRT resulted in immediate improvements on the NRS and AKET for all four patients classified with a FNHD (Table 4). Applying the PRRT hamstring treatment sequence to these patients paired with appropriate activity progression (restricted to 
Table 3. Course of Treatment Timeframe

\begin{tabular}{lccccc}
\hline Patient \# & $\begin{array}{c}\text { Time from Injury } \\
\text { to Tx (Days) }\end{array}$ & $\begin{array}{c}\text { Number of } \\
\text { Tx Sessions }\end{array}$ & $\begin{array}{c}\text { Limited Participation } \\
\text { in Sport (Days) }\end{array}$ & $\begin{array}{c}\text { Discharged } \\
\text { from Tx (Days) }\end{array}$ & $\begin{array}{c}\text { Unrestricted } \\
\text { Activity (Days) }\end{array}$ \\
\hline 1 & 1 & 3 & 2 & 4 & 3 \\
2 & $<1$ & 2 & 1 & 3 & 3 \\
3 & $<1$ & 3 & 2 & 3 & 3 \\
4 & $<1$ & 2 & 1 & 2 & 2 \\
\hline Tx = Treatment & & & & &
\end{tabular}

Table 4. Initial Pre-Intervention to Post-Intervention Outcome Scores

\begin{tabular}{lcccccccc}
\hline Patient \# & $\begin{array}{c}\text { Pre-Tx } \\
\text { NRS }\end{array}$ & $\begin{array}{c}\text { Post-Tx } \\
\text { NRS }\end{array}$ & $\begin{array}{c}\text { Pre-Tx } \\
\text { PSFS }\end{array}$ & $\begin{array}{c}\text { Post-Tx } \\
\text { PSFS }\end{array}$ & $\begin{array}{c}\text { Pre-Tx } \\
\text { AKET }\end{array}$ & $\begin{array}{c}\text { Post-Tx } \\
\text { AKET }\end{array}$ & $\begin{array}{c}\text { Pre-Tx } \\
\text { MMT }\end{array}$ & $\begin{array}{c}\text { Pre-Tx } \\
\text { MMT }\end{array}$ \\
\hline 1 & 4 & $2 \mathrm{a}$ & 5 & $8^{\mathrm{a}}$ & 55 & $67^{\mathrm{b}}$ & $2 / 5$ & $3 / 5$ \\
2 & 8 & $6^{\mathrm{a}}$ & 2 & 4 & 23 & 31 & $2 / 5$ & $2 / 5$ \\
3 & 5 & $3^{\mathrm{a}}$ & 7 & 8 & 52 & $65^{\mathrm{b}}$ & $3 / 5$ & $3 / 5$ \\
4 & 7 & $0^{\mathrm{a}}$ & 5 & 5 & 62 & $73^{\mathrm{b}}$ & $3 / 5$ & $3 / 5$ \\
\hline \multicolumn{2}{l}{ Tx = Treatment; $\mathrm{a}=$ MCID, $\mathrm{b}=$ MDC } & & & & & &
\end{tabular}

Table 5. Outcome Measurements Discharge to 6-Week Follow Up

\begin{tabular}{|c|c|c|c|}
\hline Patient \# & Discharge MMT & 1 Week MMT & 6 Week MMT \\
\hline \multicolumn{4}{|c|}{ Clinician Oriented Outcome Measures } \\
\hline \multicolumn{4}{|c|}{ Manual Muscle Testing } \\
\hline 1 & $4 / 5$ & $4+/ 5$ & $5 / 5$ \\
\hline 2 & $4+/ 5$ & $5 / 5$ & $5 / 5$ \\
\hline 3 & $5 / 5$ & $5 / 5$ & $5 / 5$ \\
\hline 4 & $4 / 5$ & $5 / 5$ & $5 / 5$ \\
\hline \multicolumn{4}{|c|}{ Active Knee Extension Test } \\
\hline 1 & $67 a / 65$ & $66 / 66$ & $72 / 75$ \\
\hline 2 & $64^{a} / 68$ & $68 / 70$ & $63 / 64$ \\
\hline 3 & $70 \propto / 74$ & $78 / 77$ & $85 / 85$ \\
\hline 4 & $73 a / 77$ & $78 / 78$ & $71 / 73$ \\
\hline \multicolumn{4}{|c|}{ Patient Oriented Outcome Measures } \\
\hline \multicolumn{4}{|c|}{ Numeric Rating Scale } \\
\hline 1 & $0^{\mathrm{b}}$ & 0 & 0 \\
\hline 2 & $2^{b}$ & 1 & 0 \\
\hline 3 & $\mathrm{O}^{\mathrm{b}}$ & 0 & 0 \\
\hline 4 & $\mathrm{O}^{\mathrm{b}}$ & 0 & 0 \\
\hline \multicolumn{4}{|c|}{ Disablement of the Physically Active } \\
\hline 1 & - & $18^{\mathrm{b}}$ & 0 \\
\hline 2 & - & $\mathrm{O}^{\mathrm{b}}$ & 0 \\
\hline 3 & - & $6^{\mathrm{b}}$ & 4 \\
\hline 4 & - & $19 \mathrm{~b}$ & 0 \\
\hline \multicolumn{4}{|c|}{ Patient Specific Functional Scale } \\
\hline 1 & $10^{\mathrm{b}}$ & 8 & 10 \\
\hline 2 & $10^{\mathrm{b}}$ & 10 & 10 \\
\hline 3 & 9 & 9 & 8 \\
\hline 4 & $9 \mathrm{~b}$ & 8 & 10 \\
\hline
\end{tabular}

AKET $=$ affected limb/unaffected limb; $a=M D C$ from discharge to unrestricted activity; $b=M C I D$ from discharge to unrestricted activity 
unrestricted activity) assisted the patients in returning to pre-injury participation levels. The focus of the four PRRT treatment techniques was on modifying the nervous system rather than a muscle tissue healing model which is commonly followed after the classification of an acute hamstring injury. Treating hamstring injuries with neurophysiological based interventions can have positive effects on pain, ROM, and function of the patient. The results of this case series support the use of intervention theories to modulate the CNS to assist patients classified with FNHD return to normalized allostatic loads demonstrated by outcomes improving before expected muscle tissue healing timeframes.

The classification of FNHD was based on the Munich muscle injury classification system. This system takes into account past classification systems based on structural damage and systems that explored functional deficits. By adding increased specifications for muscle injury, the Munich muscle injury classification system supports the use of a more patient-centered intervention approach. In patients that do not have structural muscle damage a FNMD guides clinicians to consider the neurological mechanisms of injury, which are often overlooked.

The goals for a patient following a hamstring injury is to decrease pain followed by restoring normal ROM, strength, and function, while minimizing injury recurrence rates. $1,2,7,11$ Pain management is the initial goal of any rehabilitation program. Pain could be the prolonged symptom that needs to be addressed before function can be fully restored. $6,11,33,34$ Decreasing pain is commonly achieved through heat, ice, ultrasound, electrical stimulation, mechanical therapies, and rest. $1,2,13,33-35$ Following a decrease in pain, ROM must be restored before strength and functional activities can improve. ${ }^{35-38}$ Clinicians assess musculoskeletal injuries in this manner based on a hypothesized correlation with severity of signs and symptoms. Rehabilitation is progressed based on decreased signs and symptoms assumed to be associated with tissue healing. 7,14,36,37 New classification systems are warranted as Ekstrand et al., found that patients classified with structural injuries through clinician evaluation only had evidence of MRI diagnosed muscle tear in $29 \%$ of patients. ${ }^{39}$ No diagnostic imaging was completed during this case series. Through an innovative treatment used with these patients to modify neural allostatic loads, immediate changes in pain and function occurred leading to discharge criteria being achieved faster than the traditional timeframes associated the muscle tissue healing. Each patient in this study reported immediate decreases in pain at an amount that satisfied a MCID and increased ROM greater than a MDC at the oneweek follow-up for each patient (Table 5 \& Table 6). Immediate changes in pain and ROM are useful to clinicians and further research should be completed on treatments that have similar effects.

Hamstring injury and re-injury rates have been consistent for the past 20 years and have been associated with prolonged symptoms in physically active populations. ${ }^{3-5,12}$ Most traditional treatments for acute hamstring injuries have been studied in physically active populations and include stretching techniques paired with strengthening (e.g., eccentric) exercises, and trunk stabilization and agility drill progressions. ${ }^{13,34,38}$ Most of these stretching techniques are time consuming and rely on tissue change that may not restore neuromuscular connections that are also responsible for functional deficits. Range of motion increases have been linked to sensory perception instead of the commonly cited mechanical theories to increase muscle extensibility. ${ }^{17,40}$ Currently, the best recommendations do not recommend clinicians to consider modifying the neural allostatic loads following an acute hamstring injury. ${ }^{1,2,13,35-38}$ To improve on the hamstring injury and re-injury rates new innovative treatments should be explored. Treatments that 
attempt to adjust dysregulated neural allostatic loads created during a mechanism of injury/trauma need to be considered in future research, as well as implemented into clinical practice. Sherry et al., reported that re-injury occurs in one-third of patients within two weeks of returning to unrestricted activity from a stretching and strengthening hamstring injury treatment program. ${ }^{13}$ None of the patients in the current case series suffered re-injury upon returning to full team activities at six-week follow-up which supports the effectiveness of PRRT in a short-term period.

The nervous system is sophisticated from the reflex circuits that occur at the spinal level to the descending motor pathways that control voluntary movement. Following injury or even perceived tissue damage the nervous system reacts with reflexes (e.g., flexor reflex, autogenic inhibition reflex, myotatic reflex). 19,20 Each of these movements are facilitated by an external stimulus and provide sensory information to the neurons within the spinal cord which result in motor neurons being activated to diffuse the external stimulus. When the reflex circuit is functioning appropriately the nervous system is effective at recognizing and responding to potentially dangerous external stimuli. However, in some cases external stimuli cannot be managed solely by the reflex circuit. ${ }^{40,41}$ The sensory information travels through the spinal cord to the brainstem and forebrain, which then sends a signal through the descending motor pathway to respond to the stimulus. ${ }^{19,20,40}$ If addition sensory information continues to ascend to the CNS, the allostatic load will remain increased thus leading to hypersensitivity of the nervous system. Through modulation of the CNS, reflexes can be stimulated to modify the allostatic load which would potentially result in immediate changes at the local site of musculoskeletal injury. ${ }^{22}$

There are several programs that are available to guide the treatment of acute hamstring injury.

Copyright (C) by Indiana State University All rights reserved. ISSN Online 2577-8188
Sherry et al., provided an outline of differential diagnosis, prognosis, and return to play protocol for acute hamstring injury. ${ }^{11}$ This protocol recommends 3 phases over eight weeks to progress a patient to return-to-activity. The return-to-activity was based on pain-free palpation over the injury site, full muscle strength, full muscle endurance, and no kinesiophobia. Patients classified with acute hamstring strain return-to-play in a range of 6-22 days. $4,7,13$ Gibbs et al., assessed 31 patients classified with grade I hamstring strain. Fourteen of the patients had normal MRI and returned to full team activities at an average of 6 days while 17 patients averaged 20 days to return to full team activities. ${ }^{7}$ Comparatively, the patients in this current study were discharged to return to full unrestricted activity and able to complete full team activities at 2.5 days.

With no peer-reviewed articles specific to the treatment of patients classified with acute hamstring injury, PRRT has been found to have a positive effect on pain and function when implemented in other areas of the body. Hansberger et al. reported a decrease pain in patients with chronic and acute plantar fasciitis in an intercollegiate athletic training clinic. ${ }^{24}$ The current study employed treatment procedures that were similar in design and time for intervention to the case series by Hansberger. Hansen-Honeycutt et al., reported an immediate decrease in musculoskeletal pain in three patients using PRRT and breathing reflex triggering exercises in a intercollegiate athletic training clinic. ${ }^{25}$ After utilizing these techniques, each patient reported a decrease in tenderness to palpation over his/her tender areas or with primary musculoskeletal complaint. ${ }^{25}$ The samples for both studies were patients in intercollegiate athletic training clinics. ${ }^{24,25} \mathrm{~A}$ third study was a case report on a patient with shoulder impingement syndrome treated with PRRT which resulted with immediate reduction of POE for pain, disablement, and perceived function. ${ }^{26}$ 
These examples of PRRT decreasing or resolving pain in 1 to 3 treatments warrants further investigation of this technique in other musculoskeletal disorders such as acute hamstring injury.

Based on outcomes recorded in the current study, treatments focused on modulating the CNS warrant further investigation in both clinical and laboratory settings that utilize randomized controlled methods. As expressed by the results, the intervention, PRRT, used in the current case series may have been effective at creating ideal function of the nervous system instead of a healing the tissue based on a myopic muscle tissue healing model. Future studies should incorporate a larger sample size of patients with acute hamstring injury treated and assess the effectiveness of PRRT in patients with and without $M R I$ evaluated hamstring injuries. To expand on the effectiveness of PRRT, cohort studies comparing PRRT versus other treatment interventions for acute hamstring injury would help support if the effects of this study were due to the use of PRRT.

The case series presented was the first to report the outcomes of PRRT for treating acute hamstring injury. Some of the limitations include a small sample size, and no clinician reliability. The TC was a novice practitioner with one year of clinical application of PRRT and therefore had not become an expert at the technique through years of practice. The TC providing the treatment also obtained measurements (e.g. MMT, ROM) and was not blind to results. The patients were young, physically active intercollegiate athletes therefore the effects may be expected in the same population.

\section{CLINICAL APPLICATION}

Through the case series performed by a certified athletic trainer in an athletic training clinic, the results of PRRT to treat patients with FNMD were reported. In this isolated case series patients,

Copyright (C) by Indiana State University All rights reserved. ISSN Online 2577-8188 had an immediate change in pain and ROM following treatment sessions. Treating patients classified with FNMD with PRRT led to immediate and short-term changes in the POE and COE outcomes along with successful return-to-activity. The use of PRRT possibly modified the neural allostatic load of the patient, which could explain the improved patient outcomes in the current study. The standard of care for hamstring muscle injuries is guided by the goal of creating a tissue change to decrease pain, restore function, improve strength, and limit reinjury. $1,2,7,11$ In the current study, COE and POE outcomes were positively affected in a shorter amount of time compared to pathoanatomic healing timeframe for similar patients classified with grade 1 hamstring strain. The available research on PRRT supports, through clinic practice outcomes, a neurophysiological approach to treatment of acute hamstring injury. Based on the outcomes of the study, clinicians looking to improve patient outcomes may benefit from considering a paradigm that modifies the neural allostatic loads during treatment prior to or in conjunction with other techniques rather than relying solely on the pathoanatomical theory of tissue healing.

\section{REFERENCES}

1. Clanton TO, Coupe KJ. Hamstring strains in athletes: diagnosis and treatment. J Am Acad Orthop Surg. 1998;6: 237-248.

2. Opar DA, Williams MD, Shield AJ. Hamstring strain injuries. Sports Med. 2012; 42: 209 -

26. https://doi.org/10.2165/11594800000000000-00000.

3. Malliaropoulos N, Papacostas E, Kiritsi O, Rad PM, Papalada A, Gougoulias N, Maffulli N. Posterior thigh muscle injuries in elite track and field athletes. Am J Sports Med. 2010;38: 1813-9. https://doi.org/10.1177/0363546510366 423.

4. Elliott MC, Zarins B, Powell JW, Kenyon CD. Hamstring muscle strains in professional 
football players a 10-year review. Am J

Sports Med. 2011 ; 39: 843-50.

https://doi.org/10.1177/0363546510394 647.

5. Ekstrand J, Gillquist J, Möller M, Oberg B, Liljedahl SO. Incidence of soccer injuries and their relation to training and team success.

Am J Sports Med. 1983;1 1: 63-7. https://doi.org/10.1177/0363546583011 00203.

6. Askling C, Saartok T, Thorstensson A. Type of acute hamstring strain affects flexibility, strength, and time to return to pre-injury level. Br J Sports Med. 2006;40: 40-4. https://doi.org/10.1136/bjsm.2005.01887 q.

7. Gibbs NJ, Cross TM, Cameron M, Houang MT. The accuracy of MRI in predicting recovery and recurrence of acute grade one hamstring muscle strains within the same season in Australian Rules football players. J Sci Med Sport.2004;7(2):248-58. https://doi.org/10.1016/S14402440(04)80016-1.

8. Chan O, Del Buono A, Best TM, Maffulli N. Acute muscle strain injuries: a proposed new classification system. Knee Surg Sports Traumatol Arthrosc. 2012;20(1 1):2356-62. https://doi.org/10.1007/s00167-0122118-z.

9. Morgan DL. New insights into the behavior of muscle during active lengthening. Biophys $J$. 1990;57: 209-21. https://doi.org/10.1016/500063495(90)82524-8.

10. Schuermans J, Van Tiggelen D, Danneels L, Witvrouw E. Biceps femoris and semitendinosus-teammates or competitors? New insights into hamstring injury mechanisms in male football players: a muscle functional MRI study. Br J Sports Med. 2014;48: 1599606. https://doi.org/10.1136/bjsports2014-094017.

11. Sherry MA, Johnston TS, Heiderscheit BC. Rehabilitation of acute hamstring strain

Copyright (C) by Indiana State University All rights reserved. ISSN Online 2577-8188 injuries. Clin Sports Med. 2015;34(2):263-

84.

https://doi.org/10.1016/i.csm.2014.12.009 .

12. Dalton SL, Kerr ZY, Dompier TP.

Epidemiology of hamstring strains in 25 NCAA sports in the 2009-2010 to 20132014 academic years. Am J Sports Med. 2015;43: 2671-9. https://doi.org/10.1177/0363546515599 631.

13. Sherry MA, Best TM. A comparison of 2 rehabilitation programs in the treatment of acute hamstring strains. J Orhto Sports Phys Ther. 2004;34(3): 1 16-25. https://doi.org/10.2519/iospt.2004.34.3.1 16.

14. Schneider-Kolsky ME, Hoving JL, Warren P, Connell DA. A comparison between clinical assessment and magnetic resonance imaging of acute hamstring injuries. Am J Sports Med. 2006; 34:1008-1015. https://doi.org/10.1177/0363546505283 835.

15. O'donoghue $\mathrm{DH}$. Treatment of injuries to athletes. Philadelphia, PA: WB Saunders Company; 1984.

16. Mueller-Wohlfahrt HW, Haensel L, Mithoefer K, Ekstrand J, English B, McNally S, Orchard J, van Dijk CN, Kerkhoffs GM, Schamasch P, Blottner D. Terminology and classification of muscle injuries in sport: a consensus statement. Br J Sports Med. 2012;47(6): 342-50. https://doi.org/10.1136/bjsports2012-091448.

17. Weppler $\mathrm{CH}$, Magnusson SP. Increasing muscle extensibility: a matter of increasing length or modifying sensation? Phys Ther. 2010;90: 438. https://doi.org/10.2522/pti.20090012.

18. Panjabi MM. The stabilizing system of the spine. Part I. Function, dysfunction, adaptation, and enhancement. Clin Spine Surg. 1992;5: 383-9. 
19. Yeomans JS, Li L, Scott BW, Frankland PW. Tactile, acoustic and vestibular systems sum to elicit the startle reflex. Neurosci \&

Biobehav Rev. 2002;26: 1-1. https://doi.org/10.1016/S01497634(01)00057-4.

20. Noakes TD, Peltonen JE, Rusko HK. Evidence that a central governor regulates exercise performance during acute hypoxia and hyperoxia. J Exp Biol. 2001 ;204: 3225-34.

21. Sherrington $C S$. On reciprocal innervation of antagonistic muscles. Third note. J R Soc Med. 1896;60: 414-7. https://doi.org/10.1098/rspb.1907.0026.

22. Sharman MJ, Cresswell AG, Riek S. Proprioceptive neuromuscular facilitation stretching. Sports Med. 2006;36: 929-39. https://doi.org/10.2165/00007256$200636110-00002$.

23. lams J. What is the primal reflex release technique for pain relief? 2012. Available at http://www.theprrt.com/what-is-the-primalreflex-release-technique-for-pain-relief.php. Accessed December 62016.

24. Hansberger BL, Baker RT, May J, Nasypany A. A novel approach to treating plantar fasciitis-effects of primal reflex release technique: a case series. Int J Sports Phys Ther. 2015;10(5): 690-9.

25. Hansen-Honeycutt J, Chapman EB, Nasypany A, Baker RT, May J. A clinical guide to the assessment and treatment of breathing pattern disorders in the physically active: Part 2, a case series. Int J Sports Phys Ther. 2016;11(6): 971-79.

26. Carnahan K. Inclusion of primal reflex release technique (PRRT) plan of care for shoulder pain: A case study. ND. Retrieved from http://theprrt.com/files/prrtpatientcase-study.pdf.

27. Farrar JT, Young JP, LaMoreaux L, Werth JL, Poole M. Clinical importance of changes in chronic pain intensity measured on an 11 point numerical pain rating scale. Pain. 2001;94: 149-158.
28. Vela LI, Denegar C. The disablement in the physically active scale, part II: The psychometric properties of an outcomes scale for musculoskeletal injuries. J Athl Train.

2010;45: 630-641.

https://dx.doi.org/10.4085\%2F10626050-45.6.630.

29. Hamid MS, Ali MR, Yusof A. Interrater and intrarater reliability of the active knee extension (AKE) test among healthy adults. J Phys Ther Sci. 2013;25: 957-61. https://dx.doi.org/10.1589\%2Fipts.25.957.

30. Reurink G, Goudswaard GJ, Oomen HG, Moen MH, Tol JL, Verhaar JA, Weir A. Reliability of the active and passive knee extension test in acute hamstring injuries. Am J Sports Med. 2013;41: 1757-61. https://doi.org/10.1177/0363546513490 650.

31. Kendall FP, McCreary EK, Kendall HO. Muscles, Testing and Function: Testing and Function. Philadelphia, PA: Lippincott Williams and Wilkins; 1983.32.

32. Horn KK Jennings $S$ Richardson $G$ Vliet DV Hefford C Abbott JH. The patient-specific functional scale: Psychometrics, clinimetrics, and application as a clinical outcome measure. J Orhto Sports Phys Ther. 2012;42: 30-42.

https://doi.org/10.2519/jospt.2012.3727.

33. Mason DL, Dickens V, Vail A. Rehabilitation for hamstring injuries. Cochrane Database Syst Rev. 201 2;1 2:CD004575. https://doi.org/10.1002/14651858.CD004 575.pub3.

34. Mendiguchia J, Brughelli M. A return-to-sport algorithm for acute hamstring injuries. Phys Ther Sport. 2011 ; 1 2: 2-14. https://doi.org/10.1016/i.ptsp.2010.07.00 3.

35. Copland ST, Tipton JS, Fields KB. Evidencebased treatment of hamstring tears. Curr Sports Med Reports. 2009;8: 308-14. https://doi.org/10.1249/JSR.0b013e3181c ldbel. 
36. Järvinen $T A$, Järvinen $T L$, Kääriäinen $M$, Äärimaa V, Vaittinen S, Kalimo $H$, Järvinen M. Muscle injuries: optimising recovery. Best Pract Res Clin Rheumatol. 2007;21: 317-31. https://doi.org/10.1016/i.berh.2006.12.00 4.

37. De Vos RJ, Reurink G, Goudswaard GJ, Moen $\mathrm{MH}$, Weir A, Tol JL. Clinical findings just after return to play predict hamstring reinjury, but baseline MRI findings do not. $\mathrm{Br} J$ Sports Med. 2014;48: 1377-84. https://doi.org/10.1136/bisports-2014093737.

38. Wangensteen $A$, Tol JL, Witvrouw $E$, Van Linschoten R, Almusa E, Hamilton B, Bahr R. Hamstring reinjuries occur at the same location and early after return to sport: a descriptive study of MRI-confirmed reinjuries. Am J Sports Med. 2016;44: 211 2-21. https://doi.org/10.1177/0363546516646 086.

39. Kilcoyne KG, Dickens JF, Keblish D, Rue JP, Chronister R. Outcome of Grade I and II Hamstring Injuries in Intercollegiate Athletes A Novel Rehabilitation Protocol. Sports Health. 2011 ; 3: 528-33.

https://doi.org/10.1177/1941738111422 044.

40. Ekstrand J, Askling C, Magnusson H, Mithoefer K. Return to play after thigh muscle injury in elite football players: implementation and validation of the Munich muscle injury classification. Br J Sports Med. 2013. https://doi.org/10.1136/bjsports$2012-092092$.

41. Kingsley RE. Concise Text of Neuroscience. 2nd ed. Baltimore, MD: Lippincott Williams \& Watkins; 2000. Motor systems III: The basal ganglia; 285-310.

42. Siegelbaum SA, Hudspeth AJ. Principles of neural science. Kandel ER, Schwartz JH, Jessell TM, editors. New York City, NY: McGraw-hill; 2000.

43. Turl SE, George KP. Adverse neural tension: a factor in repetitive hamstring strain? J
Orhto Sports Phys Ther. 1998;27: 16-2. https://doi.org/10.2519/iospt.1998.27.1.1 b. 